\title{
Is excess weight a burden for older adults who suffer chronic pain?
}

\author{
Huan-Ji Dong ${ }^{1 *} \mathbb{D}$, Britt Larsson', Lars-Åke Levin², Lars Bernfort ${ }^{2}$ and Björn Gerdle
}

\begin{abstract}
Background: Obesity and chronic pain are common comorbidities and adversely influence each other. Advanced age is associated with more comorbidities and multi-morbidities. In this study, we investigated the burden of overweight/obesity and its comorbidities and their associations with chronic pain in a random population sample of Swedish older adults.

Methods: The cross-sectional analysis involved a random sample of a population $\geq 65$ years in south-eastern Sweden $(N=6243)$. Data were collected from a postal questionnaire that addressed pain aspects, body mass index (BMI), and health experiences. Chronic pain was defined as pain during the previous three months. According to the 0-10 Numeric Rating Scale, pain scored $\geq 7$ corresponds to severe pain. Binary logistic regression was used to determine the variables associated to pain aspects.

Results: A total of 2633 (42\%) reported chronic pain. More obese older adults (BMI $\geq 30 \mathrm{~kg} / \mathrm{m}^{2}$ ) experienced chronic pain (58\%) than those who were low-normal weight (BMl $\left.<25 \mathrm{~kg} / \mathrm{m}^{2}, 39 \%\right)$ or overweight $(25 \leq \mathrm{BMl}$ $\left.<30 \mathrm{~kg} / \mathrm{m}^{2}, 41 \%\right)$. Obese elderly more frequently had pain in extremities and lower back than their peers. In the multivariate model, obesity (Odds Ratio (OR) 1.59, 95\% Confidence Interval (Cl) 1.33-1.91) but not overweight (OR 1.08, 95\% Cl 0.95-1.22) was associated with chronic pain. Obesity (OR 1.53, 95\% Cl 1.16-2.01) was also significantly related to severe pain. We also found other comorbidities - i.e., traumatic history (OR 2.52, 95\% Cl 1.99-3.19), rheumatic diseases (OR 5.21,95\% Cl 4.54-5.97), age $\geq 85$ years (OR 1.66, 95\% Cl 1.22-2.25), and depression or anxiety diagnosis (OR 1.83, 95\% Cl 1.32-2.53) - showed stronger associations with pain aspects than weight status. Conclusion: In older adults, excess weight (BMI 30 or above) is a potentially modifiable factor but not the only risk factor that is associated with chronic pain and severe pain. Future studies should investigate the effectiveness of interventions that treat comorbid pain and obesity in older adults.
\end{abstract}

Keywords: Chronic pain, Older adults, Obesity, Overweight

\section{Background}

Chronic pain is common in older adults, but the prevalence varies widely, ranging from 20 to $93 \%$ [1]. This wide variation is likely due to the representative population samples used and discrepancies between questionnaires that assess pain. In Sweden, more than $50 \%$ of people aged 65 and over report chronic pain [2] and in the future this percentage is likely to increase in the oldest age groups [3].

\footnotetext{
* Correspondence: huanji.dong@liu.se

${ }^{1}$ Pain and Rehabilitation Medicine, Department of Medicine and Health Sciences (IMH), Faculty of Health Sciences, Linköping University, SE-581 85 Linköping, Sweden

Full list of author information is available at the end of the article
}

The prevalence of overweight and obesity in the elderly population is increasing worldwide [4, 5]. Excess weight can affect longevity and disease-specific mortality in old age [5-7]. Rather than just surviving to an old age, more attention is now being paid to healthy aging. Both chronic pain and obesity can be barriers for healthy aging as these factors may affect important domains of life quality such as physical independence, mental well-being, and health $[8,9]$.

Obesity and chronic pain often occur simultaneously. The two conditions adversely influence each other $[10,11]$. Both in the general population and in old age groups, increased Body Mass Index (BMI) is positively related to chronic pain [12, 13], specifically in the lower limbs (i.e., hip, leg, knee, and foot) [12, 14, 15], spine (neck and back) 
$[14,16]$, and head as manifested as headaches [13, 17]. Pain can be a barrier to weight reduction. Patients with severe pain lost less weight than those with none-to-moderate pain during a weight management program, suggesting severe pain impeded their weight loss $[18,19]$. Unfortunately, current clinical practice is more likely to treat pain and excess weight as separate issues $[11,20]$. The complexity of managing each condition independently means that some other factors need to be considered.

Obesity and chronic pain share some co-morbidities (e.g., osteoarthritis, hypertension, depression, and anxiety) $[13,21-23]$ and poor health-related quality of life [4] as well as being associated with socio-demographic factors such as being female [13], low education [24], and low socio-economic status [25]. Smoking behaviour and alcohol consumption have also been considered as determinants of the relationship between obesity and chronic pain, but the literature is not entirely in agreement [24, 26-29]. However, few studies have examined weight in relation to socio-demographic profiles, comorbidities, and lifestyle habits. Moreover, the increase in life expectancy has resulted in more age-related diseases. The combination of various chronic conditions and diseases were observed frequently in aging populations [30, 31]. A majority of older adults have comorbidities and multi-morbidities [32, 33]. A knowledge gap exists as to whether, and to which extent, multiple comorbidities might substantially contribute to the weight-chronic pain relationship in old age. Using a random population sample of Swedish older adults, this cross-sectional study investigates the weight-chronic pain association with respect to sociodemographic factors, comorbidities, and lifestyle habits.

\section{Methods}

\section{Participants and procedure}

Using a cross-sectional postal questionnaire, this study collected data from a stratified random sample of 10,000 older adults ( $\geq 65$ years old) based on five age strata (65 to 69 years, 70 to 74 years, 75 to 79 years, 80 to 84 years, and 85 years and older) from the Swedish Total Population Register for the two largest cities (Linköping and Norrköping) of a county (Östergötland) in south-eastern Sweden. The questionnaire was mailed in October 2012 and, if needed, two reminders at two-week intervals were mailed. The collection of questionnaires closed in January 2013.

\section{Measurements}

The survey included several validated instruments/ scales. An overview of all parts of the survey has been presented elsewhere [34, 35]. The relevant instruments for this study are described below.

\section{Demographic aspects}

Age, sex, educational level, and civil status were recorded from the respondents' answers in the postal survey. Civil status was categorized as single, married, divorced, and widowed. Educational level was classified as high school (elementary/secondary), upper school, or vocational training for more than two years, college or university for one to two years, and college or university for three years or more.

\section{Anthropometric variables}

Height and weight were recorded from the respondents' answers in the postal survey and the BMI $\left(\mathrm{kg} / \mathrm{m}^{2}\right)$ was calculated using these data. Specifically, BMI was calculated as weight $(\mathrm{kg}) /$ height $(\mathrm{m})^{2}$ and classified according to the criteria developed by the World Health Organization (WHO): < $18.5=$ underweight; 18.5-24.9= normal range; 25.0-29.9 = overweight; and $\geq 30.0=$ obesity. Morbid obesity (severely obese) is defined as a BMI category above 35.0.

Several studies have compared the validity of measured weight- and height-calculated BMI and self-reported weight- and height-calculated BMI. High correlations were reported between the two measures (Pearson's $r=0.89$ to 0.97 for different age groups and gender) [36]. Compared to the measured BMI, self-reported BMI had a sensitivity of $88.1 \%$ and specificity of $97.4 \%$ for identifying overweight/obesity [37].

\section{Characteristics of pain}

Pain intensity over the preceding seven days was assessed using an 11-point numeric rating scale (NRS), ranging from 0 (no pain) to 10 (worst imaginable pain) [38]. The cut-offs of NRS for definitions of mild, moderate, and severe pain vary in the literature [39-42]. In this study, NRS scored 1-3, 4-6, and 7-10 corresponded to mild, moderate, and severe pain, respectively. We selected the cut-offs based on the knowledge that moderate and severe pain make it difficult with an individual's activities of daily living [42, 43]. The duration of pain was registered using one question with three alternatives: no; yes, with less duration than three months; yes, with a duration of more than three months. The present study reports the proportion with chronic pain - i.e., pain with a duration of more than three months.

All the respondents marked their painful site for the previous seven days on a body manikin divided into a total of 45 sections on the front and on the back $[44,45]$. From these sections, we identified 23 anatomical pain sites and developed a total index to denote the number of pain sites (NPS), ranging from 0 to 23 [44]. High values indicated higher spreading of pain (multi-site pain). 


\section{Co-morbidities}

The evaluation of co-morbidities was based on a 12-item self-reported list covering different aspects of common co-morbidities: (1) traumatic accident, (2) rheumatic arthritis and osteoarthritis, (3) cardiovascular diseases (including high blood pressure, angina pectoris, and heart attacks), (4) diseases of airways or lungs, (5) low mood and depression, (6) anxiety, (7) diseases of the gastrointestinal system, (8) diseases of the nervous system, including eyes and ears, (9) diseases of the urogenital organs, (10) diseases of the skin, (11) tumours and cancer, and (12) metabolic diseases such as diabetes, obesity, anorexia, bulimia, and goitre. These co-morbidities were reported on a five-point scale: $1=$ no; 2 =yes, according to both my own and my doctor's opinions; $3=$ yes, according to my own opinion; $4=$ yes, according to my doctor's opinion; and $5=$ do not know. We combined the answers for 2 and 4 to increase the robustness of measurements of the presence of a certain comorbidity. Hence, these items were dichotomized as follows: yes, according to both my own and my doctor's opinions plus according to my doctor's opinion and the three other alternatives.

\section{Life style factors}

From the instrument "Health Curve" (Hälsokurvan) [46], we chose four questions concerning smoking and snuff use that addressed both frequency (from never to daily) and number of cigarettes per day (1 to 9; 10 to 19 ; and 20 or more) and number of snuff boxes per week ( 1 to 3 per week and 7 or more per week). Five questions concerned alcohol habits. For those who confirmed alcohol consumption, the four CAGE questions (Cut-down, Annoy, Guilty, and Eye-opener) were used to screen possible alcohol addiction problems [47]; a score of $\geq 2$ was considered to indicate potential problems with alcohol abuse.

\section{Statistical analysis}

Statistical analysis was performed using the SPSS statistical package (version 22.0 IBM Inc., New York, USA). Data were reported as the mean with standard deviation (SD), the median with interquartile range (IQR), or the number with percentage based on the data distributions. Missing data were excluded from the analysis and calculated percentages were obtained from the number of valid responses. Differences among groups were assessed using the Chi-square, the one-way ANOVA, and the Kruskal-Wallis tests as appropriate. A $p$-value $<0.05$ was considered statistically significant. Binary logistic regression was used to test predictors for chronic pain, moderate pain (NRS 4-6), and severe chronic pain (NRS 7-10). BMI was entered as a categorical predictor using low-normal weight as the reference group. In the univariate analysis, we examined the effect of each variable on chronic pain, including demographic aspects (age and sex), social economic factors (marital status, education, and yearly income levels), lifestyle habits (smoking and alcohol consumption), and obesity or pain-related comorbidities. In the multivariate logistic regression, a forward (likely ratio, LR) method was used by entering each variable forwardly and removing the least significant variables from the model until all remaining variables were significant $(p<0.05$ or $p \geq 0.1$ for entry or removal, respectively). Goodness of fit was performed using the Hosmer and Lemeshow test where a $p$-value greater than 0.05 indicated good fit of the model. Collinearity was tested using a correlation matrix of estimates. Because diagnosis of depression and anxiety showed a high collinearity $(r=0.608)$, we transformed the two variables to a new variable $(1=$ depression and/or anxiety) and re-tested the correlations. This new variable represents aspects of mental health.

\section{Results}

A total of 6243 individuals completed the questionnaire including height and weight variables used to calculate BMI. For the study population, the average BMI was $25.79 \pm 4.18 \mathrm{~kg} / \mathrm{m}^{2}$ and $39 \%$ (2434) were categorized as overweight and 14\% (871) were categorized as obese. In the obesity group, $17.3 \%$ (151) were categorized as morbidly obese. Compared with the low-normal weight and the overweight groups, the obesity group was relatively younger ( $<75$ years old), had a higher proportion of males, lower education, lower yearly income, more smokers, and more suspected high alcohol consumers (Table 1).

As reported elsewhere, chronic pain was reported by $51.3 \%$ of the investigated cohort [44]. More than 55\% of the obese group had chronic pain, whereas $38.3 \%$ of the low-normal weight group and $41.8 \%$ of the overweight group had chronic pain $(p<0.001)$. Among the individuals with chronic pain, $32.7 \%$ of the obese group, $23.5 \%$ of the overweight and 20.6 of the low-normal weight (reported severe pain $(p<0.001)$. Similarly, according to NPS, the spread of chronic pain was more evident in the obese group (median $=4$ ) than in the two other groups (median 3 for both groups) $(p<0.001)$. Pain in extremities and lower back were also more prevalent in the obese group (Fig. 1). A variety of co-morbidities (e.g., rheumatic diseases, cardiovascular diseases, respiratory diseases, gastrointestinal diseases, and metabolic diseases) were more frequently reported by obese individuals than their counterparts (Table 1).

Univariate logistic regression showed that higher BMI, being female, low education (nine-year compulsory school), smoking history, high alcohol consumption, and several comorbidities were positively associated with 
Table 1 Demographic characteristics, pain aspects, and prevalence of comorbidities in the three groups of weight status

\begin{tabular}{|c|c|c|c|c|}
\hline & $\begin{array}{l}\text { Low-normal weight } \\
N=2938\end{array}$ & $\begin{array}{l}\text { Overweight } \\
N=2448\end{array}$ & $\begin{array}{l}\text { Obesity } \\
N=871\end{array}$ & $\begin{array}{l}P \text {-value } \\
\left(F \text { or } x^{2}\right)\end{array}$ \\
\hline Age, mean $\pm S D$ & $77.1 \pm 7.8$ & $75.6 \pm 7.2$ & $74.2 \pm 6.5$ & $<0.001(F=59.5)$ \\
\hline $65-74, n(\%)$ & $1218(41.5)$ & $1160(47.7)$ & $479(55)$ & $<0.001\left(x^{2}=111.5\right)$ \\
\hline $75-84, n(\%)$ & 1164 (39.6) & $982(40.3)$ & $328(37.7)$ & \\
\hline $85+, n(\%)$ & $556(18.9)$ & $292(12)$ & $64(7.3)$ & \\
\hline Female, $n(\%)$ & $1675(57)$ & $1179(48.2)$ & $481(55.2)$ & $<0.001\left(x^{2}=43.5\right)$ \\
\hline Married, $n(\%)$ & $1652(56.2)$ & $1442(58.9)$ & $497(57.1)$ & $0.129\left(x^{2}=4.10\right)$ \\
\hline Education, $n(\%)^{1}$ & & & & $<0.001\left(x^{2}=31.0\right)$ \\
\hline 9-year Compulsory school & $1393(48.9)$ & $1275(53.8)$ & $477(57)$ & \\
\hline Upper secondary school & $749(26.3)$ & $614(25.9)$ & $211(25.2)$ & \\
\hline College/University & $705(24.8)$ & $479(20.2)$ & $149(17.8)$ & \\
\hline Income (SEK per year), $n$ (\%) & & & & $<0.001\left(x^{2}=21.4\right)$ \\
\hline$<150,000$ & $872(29.7)$ & $662(27)$ & $296(34)$ & \\
\hline $150,001 \sim 220,000$ & $982(33.4)$ & $861(35)$ & 307 (35.2) & \\
\hline$>220,000$ & $1084(36.9)$ & $925(37.8)$ & $268(30.8)$ & \\
\hline Smoking, $n(\%)^{2}$ & & & & $<0.001\left(x^{2}=79.7\right)$ \\
\hline Never smoker & $1620(57.2)$ & $1244(53.1)$ & $396(48.2)$ & \\
\hline Ex-smoker & $917(32.4)$ & $955(40.8)$ & $368(44.8)$ & \\
\hline Current smoker & $295(10.4)$ & $143(6.1)$ & $57(6.9)$ & \\
\hline High alcohol consumption, $n(\%)$ & $112(3.8)$ & $118(4.8)$ & $55(6.3)$ & $0.006\left(x^{2}=10.3\right)$ \\
\hline \multicolumn{5}{|l|}{ Pain aspects, $n(\%)$} \\
\hline Chronic pain & $1134(38.6)$ & $1023(41.8)$ & $482(55.3)$ & $<0.001\left(x^{2}=77.5\right)$ \\
\hline NPS, median (IQR) ${ }^{\mathrm{a}, 3}$ & $3(1-5)$ & $3(2-5)$ & $4(2-6)$ & $<0.001\left(x^{2}=36.1\right)$ \\
\hline No pain $(\text { NRS } 0)^{a}$ & $17(1.6)$ & $12(1.2)$ & $8(1.8)$ & $<0.001\left(x^{2}=37.1\right)$ \\
\hline Mild pain (NRS 1-3) ${ }^{a}$ & $300(26.5)$ & $224(21.9)$ & $79(16.4)$ & \\
\hline Moderate pain (NRS 4-6) ${ }^{a}$ & $521(45.9)$ & $501(49)$ & $217(45)$ & \\
\hline Severe pain (NRS 7-10) ${ }^{a}$ & $218(20.6)$ & $226(23.5)$ & $148(32.7)$ & \\
\hline \multicolumn{5}{|l|}{ Comorbidities, n (\%) } \\
\hline History of trauma or injury accident & $190(6.5)$ & $183(7.5)$ & $64(7.3)$ & $0.340\left(x^{2}=2.30\right)$ \\
\hline Rheumatic diseases & $638(21.7)$ & $637(26)$ & $327(37.5)$ & $<0.001\left(x^{2}=88.7\right)$ \\
\hline Cardiovascular diseases & $1242(42.3)$ & $1301(53.1)$ & $553(63.5)$ & $<0.001\left(x^{2}=142.6\right)$ \\
\hline Respiratory diseases & $317(10.8)$ & $264(10.8)$ & $155(17.8)$ & $<0.001\left(x^{2}=35.5\right)$ \\
\hline Gastrointestinal diseases & $411(14)$ & $378(15.4)$ & $167(19.2)$ & $0.001\left(x^{2}=14.0\right)$ \\
\hline Neurological diseases & $914(31.1)$ & $731(29.9)$ & $228(26.2)$ & $0.02\left(x^{2}=7.80\right)$ \\
\hline Urogenital diseases & $240(8.2)$ & $213(8.7)$ & $87(10)$ & $0.238\left(x^{2}=2.85\right)$ \\
\hline Metabolic diseases & $290(9.9)$ & $379(15.6)$ & $274(31.5)$ & $<0.001\left(x^{2}=244.8\right)$ \\
\hline Cancer diagnosis & $230(7.8)$ & $178(7.3)$ & $64(7.3)$ & $0.723\left(x^{2}=0.65\right)$ \\
\hline Depression & $132(4.5)$ & $105(4.3)$ & $48(5.5)$ & $0.337\left(x^{2}=2.18\right)$ \\
\hline Anxiety & $129(4.4)$ & $97(4)$ & $47(5.4)$ & $0.217\left(x^{2}=3.06\right)$ \\
\hline
\end{tabular}

The far right column shows the result of the omnibus statistical testing ( $p$-value, $F$ and $x^{2}$ ) NPS number of pain sites; ${ }^{a}$ Individuals with chronic pain $N=2639$ Missing data: ${ }^{1}=205 ;^{2}=262 ;^{3}=168$

chronic pain (Table 2). Most of these positive effects remained in the multivariate regression, except for being overweight, education, yearly income, high alcohol consumption, and having cardiovascular diseases or cancer (Table 2). Being obese (OR 1.59, 95\% CI 1.32-1.91, $p<0.001$ ) but not overweight (OR 1.08, 95\% CI 0.95- 


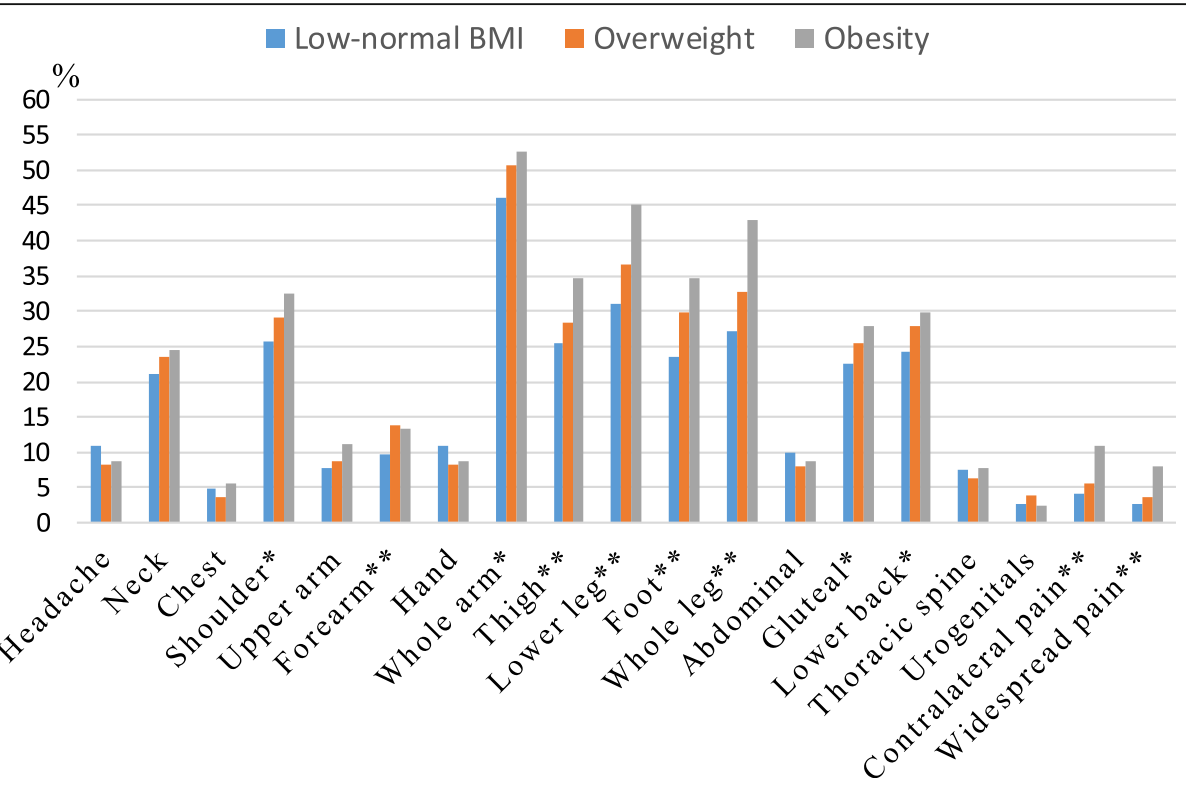

Fig. 1 Prevalence of pain in 23 anatomical regions with BMI stratifications. The regions of head, shoulder, upper arm, forearm, hand, thigh, lower leg, and foot included both right and left sides. ${ }^{*} P<0.05,{ }^{* *} P<0.01$

1.21, $p=0.254$ ) was more likely associated with chronic pain than low-normal weight. Some factors, such as having trauma or injury accident history (OR 2.52, 95\% CI: 1.99-3.19) and rheumatic diseases (OR 5.21, 95\% CI: 4.54-5.97), showed higher associations with chronic pain than obesity status.

Within the chronic pain group, obesity and overweight were weakly but significantly associated with moderate pain (OR1.30-1.39, $p<0.05$, Table 2). In comparison, obesity had stronger impact on severe pain (OR 1.53, 95\% CI 1.16-2.01, $p<0.01)$. However, aged 85 and over (OR 1.66, 95\% CI 1.22-2.25) and depression and/or anxiety diseases (OR 1.83, 95\% CI 1.32-2.53) were more strongly linked to severe pain than being obese. Sociodemographic factors such as age, gender, education, and income levels were also significantly related to having moderate pain. Being an ex-smoker, certain co-morbidities (e.g., rheumatic diseases and cardiovascular diseases), and number of pain sites were also significant regressors of severe pain.

\section{Discussion}

Among the older adults in our study cohort, chronic pain was more common in people categorized as obese than in people categorized as overweight or low-normal weight. A distinct difference in anatomical pain distributions to some extent reflected the negative consequence of excess weight. The well-known disparity of pain distributions with respect to sex [13,48-51] was also found in the cohort, but this was not statistically significant across age stratifications. Our findings contribute to the growing body of evidence that being obese, but not being overweight, is closely related to chronic pain, including severe chronic pain in the older adults. Furthermore, in our aged sample, having multiple comorbidities was more strongly related to pain-related factors than excess weight.

In the context of the current obesity epidemic, the adverse health consequences of excess weight place older adults at risk for comorbidity, poor physical function, and disability. In later life, chronic pain may show a mediating effect between obesity and these consequences [52]. The literature identifies three dominant aspects that support the relationship between obesity and chronic pain. First, increased mechanical load could explain the connection between excess weight and specific anatomical pain distributions [10, 21]. In our study, this hypothesis was reasonably confirmed by a higher proportion of reported chronic pain in extremities and low back in obese olds than in normal-weight or overweight olds. Second, hyperalgesia can be the result of the gradual development of systematic chronic low-grade inflammation. For example, pain can be modulated by inflammatory processes initiated by altered levels of cytokines ( $C$ creative protein, interlukin- 6 , TNF- $\alpha$, IL-6, adiponectin, leptin, resistin, and visfatin) in adipose tissue $[10,21,53,54]$. Furthermore, aging contributes to a pro-inflammatory state by increasing production of cytokines and reducing the capacity to cope with a variety of stressors [55]. Our multivariate models showed that the influence of age on inflammation may contribute to the course of chronic pain and to the increase in pain intensity. Third, obese adults are more likely to suffer poor mental health [56, 57], adding to their inflammation-inducing 
Table 2 Univariate and multivariate logistic regression - factors associated with chronic pain and severe pain

\begin{tabular}{|c|c|c|c|c|}
\hline & \multicolumn{2}{|c|}{ Variables associated with Chronic pain } & \multirow{2}{*}{$\begin{array}{l}\text { Variables associated with } \\
\text { moderate pain } \\
\text { Multivariate } \\
{[\text { OR }(95 \% \mathrm{Cl})]}\end{array}$} & \multirow{2}{*}{$\begin{array}{l}\text { Variables associated } \\
\text { with severe pain } \\
\text { Multivariate } \\
{[\text { OR }(95 \% \mathrm{Cl})]}\end{array}$} \\
\hline & $\begin{array}{l}\text { Univariate } \\
{[\text { OR }(95 \% \mathrm{Cl})]}\end{array}$ & $\begin{array}{l}\text { Multivariate } \\
{[\text { OR }(95 \% \mathrm{Cl})]}\end{array}$ & & \\
\hline BMI (Low-normal BMI reference category) & 1.0 & 1.0 & 1.0 & 1.0 \\
\hline Overweight & $1.14(1.02-1.27)$ & $1.08(0.95-1.22)$ & $1.30(1.04-1.63)^{*}$ & $1.09(0.87-1.34)$ \\
\hline Obesity & $1.97(1.69-2.30)$ & $1.59(1.33-1.91)^{* *}$ & $1.39(1.02-1.89)^{*}$ & $1.53(1.17-2.01)^{* *}$ \\
\hline Age (65-74 y, reference category) & 1.0 & - & 1.0 & 1.0 \\
\hline $75-84$ y & $1.04(0.93-1.16)$ & - & $1.11(0.89-1.40)$ & $1.31(1.05-1.63)^{*}$ \\
\hline $85+y$ & $1.05(0.90-1.22)$ & - & $1.81(1.26-2.60)^{* *}$ & $1.66(1.22-2.25)^{* *}$ \\
\hline Gender ( 1 = female) & $1.66(1.50-1.84)^{* *}$ & $1.40(1.24-1.58)^{* *}$ & $1.33(1.06-1.67)^{*}$ & - \\
\hline Marital status $(1=$ married $)$ & $0.91(0.83-1.01)$ & - & - & - \\
\hline Education (College/university, reference category) & 1.0 & - & 1.0 & - \\
\hline 9-year Compulsory school & $1.32(1.16-1.50)^{* *}$ & - & $1.47(1.11-1.94)^{*}$ & - \\
\hline Upper secondary school & $1.13(0.98-1.32)$ & - & $1.33(0.99-1.79)$ & - \\
\hline Income per year ( $<150,000$ SEK, reference category) & 1.0 & - & 1.0 & - \\
\hline $150,001 \sim 220,000$ & $0.83(0.73-0.94)^{*}$ & - & $0.78(0.58-1.02)$ & - \\
\hline$>220,000$ & $0.64(0.57-0.73)^{* *}$ & - & $0.70(0.51-0.95)^{*}$ & - \\
\hline Smoking (never smoker, reference category) & 1.0 & 1.0 & - & 1.0 \\
\hline Ex-smoker, $n \%$ & $1.14(1.02-1.27)^{*}$ & $1.21(1.07-1.38)^{*}$ & - & $1.30(1.05-1.60)^{*}$ \\
\hline Current smoker, $n \%$ & $1.13(0.93-1.36)$ & $1.29(1.04-1.59)^{*}$ & - & $1.33(0.93-1.91)$ \\
\hline High alcohol consumption ( 1 =yes) & $1.17(0.92-1.48)$ & - & - & - \\
\hline History of trauma or injury accident & $3.2(2.60-3.94)^{* *}$ & $2.52(1.99-3.19)^{* *}$ & - & - \\
\hline Rheumatic diseases ( $1=$ yes) & $5.92(5.22-6.72)^{* *}$ & $5.21(4.54-5.97)^{* *}$ & - & $1.34(1.10-1.64)^{*}$ \\
\hline Cardiovascular diseases ( $1=$ yes $)$ & $1.35(1.22-1.49)^{* *}$ & - & $1.36(1.10-1.67)^{* *}$ & $1.33(1.10-1.64)^{*}$ \\
\hline Respiratory diseases $(1=$ yes $)$ & $1.82(1.56-2.12)^{* *}$ & $1.34(1.18-1.52)^{* *}$ & - & - \\
\hline Gastrointestinal diseases ( $1=$ yes) & $2.61(2.35-3.16)^{* *}$ & $1.93(1.64-2.27)^{* *}$ & - & - \\
\hline Neurological diseases ( $1=$ yes) & $1.71(1.54-1.91)^{* *}$ & $1.34(1.18-1.52)^{* *}$ & - & - \\
\hline Urogenital diseases $(1=$ yes $)$ & $1.53(1.36-1.97)^{* *}$ & - & - & - \\
\hline Metabolic diseases ( $1=$ yes $)$ & $1.59(1.43-1.91)^{* *}$ & $1.27(1.08-1.50)^{*}$ & - & - \\
\hline Cancer diagnosis $(1=$ yes $)$ & $1.33(1.07-1.57)^{*}$ & - & - & - \\
\hline Depression and/or anxiety ( $1=$ yes) & $1.99(1.61-2.45)^{* *}$ & $1.46(1.14-1.86)^{*}$ & - & $1.83(1.32-2.53)^{* *}$ \\
\hline Number of pain sites (NPS) & & & $1.11(1.06-1.16)^{* *}$ & $1.1(1.06-1.13)^{*}$ \\
\hline Model Nagelkerke $R^{2}$ & & 0.236 & 0.086 & 0.08 \\
\hline Model Hosmer and Lemeshow test & & $x^{2}=7.63, P=0.47$ & $x^{2}=10.40, P=0.238$ & $x^{2}=6.30, P=0.613$ \\
\hline
\end{tabular}

stressors. Previous studies have recognized this co-existence and interactions between mood disorders (depression and/or anxiety) and pain [58-61]. Because the associations between these conditions are bidirectional, it is difficult to ascertain which condition causes or exacerbates the other or indeed if a causal relationship exists.

Smoking history seems to play an important role in the course of chronic pain and severe pain. As with other studies, we found that both current smoking and ex-smoking were associated with chronic pain [62-64]; however, determining the underlying mechanism is difficult as thousands of compounds in cigarette smoke produce physiological effects. Apart from the pharmacological effect of nicotine and other ligands at the nicotinic acetylcholine receptor associated with pain, smoking behaviour to some extent reflects poor mental well-being [65]. Smoking as an unhealthy behaviour is part of negative psychological profiles and it is interconnected with obesity and pain symptoms [26, 27, 65].

In the multivariate model, we found several common comorbidities (e.g., rheumatic diseases) of chronic pain that have a greater impact than obesity. In the logistic 
regressions, we found that other obesity-related diseases/co-morbidities - e.g., obstructive sleep apnoea (categorized as a respiratory disease), gallbladder disorder (categorized as a gastrointestinal disease), stroke (categorized as a neurological disease), diabetes (categorized as a metabolic disease), and mental illness (depression or anxiety) - exhibited a modest association with chronic pain. These impacts may have been stronger if these diseases/co-morbidities had been asked for specifically and not included in broader categories as in the present study. Therefore, in an aging population with a high prevalence of multiple morbidities, we need to consider the above common comorbidities when evaluating chronic pain and suffering. In addition, these comorbidities are not the same comorbidities younger people experiece when suffering from chronic pain. For example, unlike a chronic pain study of younger people [26], two common obesity-related illnesses, cancer and cardiovascular disease, were not significantly associated with chronic pain in our study population. This difference suggests that the relationship between these conditions and chronic pain in old age are weaker or even absent. It may be that these common comorbidities are also age-related, so they may frequently occur in older adults with or without excess weight and pain suffering.

The analysis of these factors together with weight status provides a subset of the aging population who may be more likely to have chronic pain. To meet the particular needs of pain management for older people (e.g., pharmacological treatment, lifestyle interventions, psychological support, and rehabilitation) [66], health professionals should identify the risk group. Our study results support the growing evidence of the pain-obesity relationship in older adults. The multivariate models strongly indicate the need to have a multifactorial approach to chronic pain when assessing patients with pain. Our results indicate the need to incorporate weight/BMI as one of several factors in such assessments. It is important to be aware that not all risk factors in the models are modifiable - i.e., increased age, female gender, education, income, and having trauma history. Alternatively, the modifiable factors such as obesity, smoking, and certain chronic diseases present the opportunities for intervening. Because more modifiable factors existed in patients with severe pain than in patients with moderate pain, patients with severe pain have more interventions available to them that can relieve their pain. Healthcare professionals need to pay attention to existing multifactorial characteristics so they can identify the people at greatest risk and in most need of interventions. Therefore, pain interventions for older adults should direct their focus on the modifiable risk factors.
One important limitation of this cross-sectional study was the bias from self-reported anthropometric measures. Despite a high correlation between self-reported and measured values, the underestimation of excess weight by self-reported values has been reported [36, 37]. If we consider this bias (men by 1-unit and women by 1.19-unit underestimated BMI) [37], a total of 1117 individuals could be misclassified (28.5\% of normal-weight and $14.5 \%$ of overweight). When we recalculated the regression analysis using these revised numbers, the estimates in the model did not show significant changes (data not shown).

Another weakness of our study could be the lack of generalizability of the results due to the rate of non-participants in the study population, with a valid response of $62.7 \%$ (10,000 subjects selected) [34]. The non-participants may represent a group with severe illness (e.g., admitted in hospital, residing in nursing homes, and unable to answer the questionnaire due to cognitive impairment) or a more healthy group (e.g., without any pain discomforts) so they were not interested in participating in the study [67].

In addition, our cross-sectional analysis did not uncover any causation. We cannot identify a direct cause-and-effect relationship between these factors. The results should be tested longitudinally in future studies. Additionally, although many important co-variates were included in the regression analysis, some potentially meaningful co-variates such as dietary intake and physical activity were not collected in this study. Previous studies demonstrated that unhealthy excess food intake and sedentary living cause weight gain and systemic inflammation [68, 69]. To some extent, this understanding provides for the possibility that interventions could break down the vicious circle of excess weight and chronic pain conditions. A follow-up study or longitudinal studies measuring changes could validate the impacts of changes on comorbid obesity and pain.

\section{Conclusion}

Chronic pain affects more obese older adults than their low-normal or overweight peers. Excess weight (BMI 30 or above) is a potentially modifiable factor but not the only risk factor that is associated with chronic pain and severe pain. It is important for healthcare professionals to understand the multiple factors involved in the complex relationship between pain and excess weight. Healthcare professionals and policy makers should address the management of the coexisting modifiable factors instead of focusing on a single achievement (i.e., weight reduction). Future research should investigate the effectiveness of interventions that treat comorbid pain and obesity in older adults. 


\section{Abbreviations}

BMI: Body Mass Index; Cl: Confidence Interval; NPS: Number of Pain Sites; NRS: Numeric Rating Scale; OR: Odds ratio

\section{Acknowledgments}

The authors acknowledge and thank the participants.

\section{Funding}

The present study was sponsored by a grant from Grünenthal Sweden AB.

\section{Availability of data and materials}

The data collected in the present study, according to Swedish laws and regulations, are considered sensitive data although data from specific individuals cannot be identified. The ethical approval only included permission to publish results on group levels.

\section{Authors' contributions}

$B L, L-A ̊ L, L B$, and $B G$ made substantial contributions to study conception and design. $\mathrm{H}-\mathrm{J} \mathrm{D}$ and $\mathrm{BG}$ performed the data analyses and took part in drafting the manuscript. All authors discussed the results and revised it critically. All authors had full access to all the data in the study and had final responsibility for the decision to submit for publication.

\section{Ethics approval and participant consent}

The study was approved by the Regional Ethics Research Committee in Östergötland, Sweden (D.nr. 2012/154-31). Patient-informed consent was assumed through the completion and the return of the postal surveys.

\section{Consent for publication}

Not applicable.

\section{Competing interests}

The sponsor of the study had no role in study design, data collection, data analysis, data interpretation, writing of the report, or the decision to submit for publication. The authors had full access to all the data in the study and had final responsibility for the decision to submit for publication. The authors declare that they have no competing interests.

\section{Publisher's Note}

Springer Nature remains neutral with regard to jurisdictional claims in published maps and institutional affiliations.

\section{Author details}

${ }^{1}$ Pain and Rehabilitation Medicine, Department of Medicine and Health Sciences (IMH), Faculty of Health Sciences, Linköping University, SE-581 85 Linköping, Sweden. ${ }^{2}$ Division of Health Care Analysis, Department of Medical and Health Sciences, Linköping University, SE-581 85 Linköping, Sweden.

Received: 7 December 2017 Accepted: 24 October 2018

Published online: 08 November 2018

\section{References}

1. Abdulla A, Adams N, Bone M, Elliott AM, Gaffin J, Jones D, Knaggs R, Martin D, Sampson L, Schofield P. Guidance on the management of pain in older people. Age Ageing. 2013;42(Suppl 1):i1-57.

2. Gerdle B, Bjork J, Henriksson C, Bengtsson A. Prevalence of current and chronic pain and their influences upon work and healthcare-seeking: a population study. J Rheumatol. 2004;31(7):1399-406.

3. Ahacic K, Kareholt I. Prevalence of musculoskeletal pain in the general Swedish population from 1968 to 2002: age, period, and cohort patterns. Pain. 2010;151(1):206-14.

4. Salihu HM, Bonnema S, Alio AP. Obesity: what is an elderly population growing into? Maturitas. 2009;63(1):7-12.

5. Chapman IM. Obesity paradox during aging. Interdiscip Top Gerontol. 2010:37:20-36.

6. Zamboni M, Mazzali G, Zoico E, Harris TB, Meigs JB, Di Francesco V, Fantin F, Bissoli L, Bosello O. Health consequences of obesity in the elderly: a review of four unresolved questions. Int J Obes. 2005;29(9):1011-29.

7. Flegal KM, Kit BK, Orpana H, Graubard BI. Association of all-cause mortality with overweight and obesity using standard body mass index categories: a systematic review and meta-analysis. JAMA. 2013;309(1):71-82.
8. Anton SD, Woods AJ, Ashizawa T, Barb D, Buford TW, Carter CS, Clark DJ, Cohen RA, Corbett DB, Cruz-Almeida Y, et al. Successful aging: advancing the science of physical independence in older adults. Ageing Res Rev. 2015;24(Pt B):304-27.

9. Depp CA, Jeste DV. Definitions and predictors of successful aging: a comprehensive review of larger quantitative studies. Am J Geriatr Psychiatry. 2006;14(1):6-20.

10. Okifuji A, Hare BD. The association between chronic pain and obesity. J Pain Res. 2015:8:399-408.

11. Cooper L, Ells L, Ryan C, Martin D. Perceptions of adults with overweight/ obesity and chronic musculoskeletal pain: an interpretative phenomenological analysis. J Clin Nurs. 2018;27(5-6):e776-86.

12. Hitt HC, McMillen RC, Thornton-Neaves T, Koch K, Cosby AG. Comorbidity of obesity and pain in a general population: results from the southern pain prevalence study. J Pain. 2007;8(5):430-6.

13. McCarthy LH, Bigal ME, Katz M, Derby C, Lipton RB. Chronic pain and obesity in elderly people: results from the Einstein aging study. J Am Geriatr Soc. 2009;57(1):115-9.

14. Andersen RE, Crespo CJ, Bartlett SJ, Bathon JM, Fontaine KR. Relationship between body weight gain and significant knee, hip, and back pain in older Americans. Obes Res. 2003:11(10):1159-62.

15. Fransen M, Su S, Harmer A, Blyth FM, Naganathan V, Sambrook P, Le Couteur D, Cumming RG. A longitudinal study of knee pain in older men: Concord health and ageing in men project. Age Ageing. 2014:43(2):206-12.

16. Fernandez-de-las-Penas C, Hernandez-Barrera V, Alonso-Blanco C, PalaciosCena D, Carrasco-Garrido P, Jimenez-Sanchez S, Jimenez-Garcia R. Prevalence of neck and low back pain in community-dwelling adults in Spain: a population-based national study. Spine. 2011;36(3):E213-9.

17. Bigal ME, Rapoport AM. Obesity and chronic daily headache. Curr Pain Headache Rep. 2012;16(1):101-9.

18. Masheb RM, Lutes LD, Kim HM, Holleman RG, Goodrich DE, Janney CA, Kirsh S, Higgins DM, Richardson CR, Damschroder $\amalg$. Weight loss outcomes in patients with pain. Obesity. 2015;23(9):1778-84.

19. Ryan CG, Vijayaraman A, Denny V, Ogier A, Ells L, Wellburn S, Cooper L, Martin DJ, Atkinson $\mathrm{G}$. The association between baseline persistent pain and weight change in patients attending a specialist weight management service. PLoS One. 2017;12(6):e0179227.

20. Cooper L, Ryan CG, Ells LJ, Hamilton S, Atkinson G, Cooper K, Johnson MI, Kirwan JP, Martin D. Weight loss interventions for adults with overweight/ obesity and chronic musculoskeletal pain: a mixed methods systematic review. Obes Rev. 2018;19(7):989-1007.

21. Taylor R, Pergolizzi JV, Raffa RB, Nalamachu S, Balestrieri PJ. Pain and obesity in the older adult. Curr Pharm Des. 2014;20(38):6037-41.

22. Wright L, Schur E, Noonan C, Ahumada S, Buchwald D, Afari N. Chronic pain, overweight, and obesity: findings from a community-based twin registry. J Pain. 2010;11(7):628-35.

23. Reeuwijk KG, de Rooij M, van Dijk GM, Veenhof C, Steultjens MP, Dekker J. Osteoarthritis of the hip or knee: which coexisting disorders are disabling? Clin Rheumatol. 2010;29(7):739-47.

24. Stone AA, Broderick JE. Obesity and pain are associated in the United States. Obesity. 2012;20(7):1491-5.

25. Ahn S, Huber C, Smith ML, Ory MG, Phillips CD. Predictors of body mass index among low-income community-dwelling older adults. J Health Care Poor Underserved. 2011;22(4):1190-204.

26. Shi Y, Hooten WM, Roberts RO, Warner DO. Modifiable risk factors for incidence of pain in older adults. Pain. 2010;151(2):366-71.

27. van Hecke O, Torrance N, Smith BH. Chronic pain epidemiology - where do lifestyle factors fit in? Br J Pain. 2013;7(4):209-17.

28. Mourao AF, Blyth FM, Branco JC. Generalised musculoskeletal pain syndromes. Best Pract Res Clin Rheumatol. 2010;24(6):829-40.

29. Brennan PL, Schutte KK, Moos RH. Pain and use of alcohol to manage pain: prevalence and 3-year outcomes among older problem and non-problem drinkers. Addiction. 2005;100(6):777-86.

30. Barnett K, Mercer SW, Norbury M, Watt G, Wyke S, Guthrie B. Epidemiology of multimorbidity and implications for health care, research, and medical education: a cross-sectional study. Lancet. 2012;380(9836):37-43.

31. Islam MM, Valderas JM, Yen L, Dawda P, Jowsey T, McRae IS. Multimorbidity and comorbidity of chronic diseases among the senior Australians: prevalence and patterns. PLoS One. 2014;9(1):e83783.

32. Salive ME. Multimorbidity in older adults. Epidemiol Rev. 2013;35:75-83. 
33. Marengoni A, Angleman S, Melis R, Mangialasche F, Karp A, Garmen A Meinow B, Fratiglioni L. Aging with multimorbidity: a systematic review of the literature. Ageing Res Rev. 2011;10(4):430-9.

34. Bernfort L, Gerdle B, Rahmqvist M, Husberg M, Levin LA. Severity of chronic pain in an elderly population in Sweden--impact on costs and quality of life. Pain. 2015;156(3):521-7.

35. Larsson B, Gerdle B, Bernfort L, Levin LA, Dragioti E. Distinctive subgroups derived by cluster analysis based on pain and psychological symptoms in Swedish older adults with chronic pain - a population study (PainS65+). BMC Geriatr. 2017;17(1):200.

36. Kuczmarski MF, Kuczmarski RJ, Najjar M. Effects of age on validity of selfreported height, weight, and body mass index: findings from the third National Health and nutrition examination survey, 1988-1994. J Am Diet Assoc. 2001;101(1):28-34 quiz 35-26.

37. Vuksanović M, Safer A, Palm F, Stieglbauer G, Grau A, Becher H. Validity of self-reported BMI in older adults and an adjustment model. J Public Health. 2014;22(3):257-63.

38. Ferreira-Valente MA, Pais-Ribeiro JL, Jensen MP. Validity of four pain intensity rating scales. Pain. 2011;152(10):2399-404.

39. Hirschfeld G, Zernikow B. Variability of "optimal" cut points for mild, moderate, and severe pain: neglected problems when comparing groups. Pain. 2013;154(1):154-9.

40. Fejer R, Jordan A, Hartvigsen J. Categorising the severity of neck pain: establishment of cut-points for use in clinical and epidemiological research. Pain. 2005;119(1-3):176-82.

41. Turner JA, Franklin G, Heagerty PJ, Wu R, Egan K, Fulton-Kehoe D, Gluck JV, Wickizer TM. The association between pain and disability. Pain. 2004;112(3):307-14.

42. Jensen M. The pain stethoscope. In: A clinician's guide to measuring pain, vol. IX. London: Springer Healthcare Communications; 2011. p. 53.

43. Breivik H, Collett B, Ventafridda V, Cohen R, Gallacher D. Survey of chronic pain in Europe: prevalence, impact on daily life, and treatment. Eur J Pain. 2006;10(4):287-333.

44. Dragioti E, Larsson B, Bernfort L, Levin LA, Gerdle B. Prevalence of different pain categories based on pain spreading on the bodies of older adults in Sweden: a descriptive-level and multilevel association with demographics, comorbidities, medications, and certain lifestyle factors (PainS65+). J Pain Res. 2016:9:1131-41.

45. Grimby-Ekman A, Gerdle B, Bjork J, Larsson B. Comorbidities, intensity, frequency and duration of pain, daily functioning and health care seeking in local, regional, and widespread pain - a descriptive population-based survey (SwePain). BMC Musculoskelet Disord. 2015;16:165.

46. Persson LG, Lindstrom $K$, Lingfors $H$, Bengtsson $C$. A study of men aged 33-42 in Habo, Sweden with special reference to cardiovascular risk factors. Design, health profile and characteristics of participants and nonparticipants. Scand J Soc Med. 1994;22(4):264-72.

47. Persson LG, Lindstrom K, Lingfors H, Bengtsson C, Lissner L. Cardiovascular risk during early adult life. Risk markers among participants in "live for life" health promotion programme in Sweden. J Epidemiol Community Health. 1998:52(7):425-32.

48. Rustoen T, Wahl AK, Hanestad BR, Lerdal A, Paul S, Miaskowski C. Gender differences in chronic pain--findings from a population-based study of Norwegian adults. Pain Manag Nurs. 2004;5(3):105-17.

49. Miro J, Paredes S, Rull M, Queral R, Miralles R, Nieto R, Huguet A, Baos J. Pain in older adults: a prevalence study in the Mediterranean region of Catalonia. Eur J Pain. 2007;11(1):83-92.

50. Patel KV, Guralnik JM, Dansie EJ, Turk DC. Prevalence and impact of pain among older adults in the United States: findings from the 2011 National Health and aging trends study. Pain. 2013;154(12):2649-57.

51. Blyth FM, March LM, Brnabic AJ, Jorm LR, Williamson M, Cousins MJ. Chronic pain in Australia: a prevalence study. Pain. 2001;89(2-3):127-34.

52. Fowler-Brown A, Wee CC, Marcantonio E, Ngo L, Leveille S. The mediating effect of chronic pain on the relationship between obesity and physical function and disability in older adults. J Am Geriatr Soc. 2013;61(12):2079-86.

53. Hauner $\mathrm{H}$. Secretory factors from human adipose tissue and their functional role. Proc Nutr Soc. 2005;64(2):163-9.

54. Bas S, Finckh A, Puskas GJ, Suva D, Hoffmeyer P, Gabay C, Lubbeke A. Adipokines correlate with pain in lower limb osteoarthritis: different associations in hip and knee. Int Orthop. 2014;38(12):2577-83.
55. Franceschi C, Bonafe M, Valensin S, Olivieri F, De Luca M, Ottaviani E, De Benedictis $\mathrm{G}$. Inflamm-aging. An evolutionary perspective on immunosenescence. Ann N Y Acad Sci. 2000;908:244-54.

56. Hassan MK, Joshi AV, Madhavan SS, Amonkar MM. Obesity and healthrelated quality of life: a cross-sectional analysis of the US population. Int J Obes Relat Metab Disord. 2003;27(10):1227-32.

57. Simon GE, Von Korff M, Saunders K, Miglioretti DL, Crane PK, van Belle G, Kessler RC. Association between obesity and psychiatric disorders in the US adult population. Arch Gen Psychiatry. 2006;63(7):824-30.

58. El-Gabalawy R, Mackenzie CS, Shooshtari S, Sareen J. Comorbid physical health conditions and anxiety disorders: a population-based exploration of prevalence and health outcomes among older adults. Gen Hosp Psychiatry. 2011;33(6):556-64

59. Li JX. Pain and depression comorbidity: a preclinical perspective. Behav Brain Res. 2015;276c:92-8.

60. Okifuji ATD. Chronic pain and depression: vulnerability and resilience. In: aAM FMA, editor. Neuroscience of pain, stress, and emotion. New York: Elsevier; 2015.

61. Aguera-Ortiz L, Failde I, Cervilla JA, Mico JA. Unexplained pain complaints and depression in older people in primary care. J Nutr Health Aging. 2013;17(6):574-7.

62. Jakobsson U. Tobacco use in relation to chronic pain: results from a Swedish population survey. Pain Med. 2008;9(8):1091-7.

63. John U, Hanke M, Meyer C, Volzke H, Baumeister SE, Alte D. Tobacco smoking in relation to pain in a national general population survey. Prev Med. 2006:43(6):477-81.

64. Palmer KT, Syddall H, Cooper C, Coggon D. Smoking and musculoskeletal disorders: findings from a British national survey. Ann Rheum Dis. 2003;62(1):33-6.

65. Shi Y, Weingarten TN, Mantilla CB, Hooten WM, Warner DO. Smoking and pain: pathophysiology and clinical implications. Anesthesiology. 2010;113(4):977-92.

66. Kaye AD, Baluch A, Scott JT. Pain management in the elderly population: review. Ochsner J. 2010;10(3):179-87.

67. Hardy SE, Allore H, Studenski SA. Missing data: a special challenge in aging research. J Am Geriatr Soc. 2009;57(4):722-9.

68. Arranz LI, Rafecas M, Alegre C. Effects of obesity on function and quality of life in chronic pain conditions. Curr Rheumatol Rep. 2014;16(1):390.

69. Emery CF, Olson KL, Bodine A, Lee V, Habash DL. Dietary intake mediates the relationship of body fat to pain. Pain. 2017;158(2):273-7.

\section{Ready to submit your research? Choose BMC and benefit from:}

- fast, convenient online submission

- thorough peer review by experienced researchers in your field

- rapid publication on acceptance

- support for research data, including large and complex data types

- gold Open Access which fosters wider collaboration and increased citations

- maximum visibility for your research: over $100 \mathrm{M}$ website views per year

At $\mathrm{BMC}$, research is always in progress.

Learn more biomedcentral.com/submissions 